\title{
Artículos
}

\section{Justicia transicional y los significados de la elaboración del pasado nicaragüense}

\section{Anika Oettler*}

\section{Recibido: junio de 2013 / Aceptado: julio de 2013}

En el discurso global sobre justicia transicional, Nicaragua es tratada como un caso divergente porque el imperativo ético de justicia y reconciliación no fue tomado en cuenta después de la derrota electoral sandinista de 1990. Partiendo del debate semántico sobre la idea de la 'superación del pasado', el artículo contrasta las dos transiciones nicaragüenses (1979 y 1990), identificando los factores que influyeron en la aplicación u omisión de medidas de justicia transicional. La justicia transicional revolucionaria, después del triunfo de 1979, fue caracterizada por el establecimiento de Tribunales Especiales que sirvieron para castigar a los miles de somocistas, sobrepoblando los centros de detención. En el marco de la segunda transición -la derrota electoral sandinista de 1990- no se aplicaron medidas de justicia transicional. En ambos casos, la política de pacificación se caracterizó por el enfoque en el desarme de los combatientes y por la ausencia de la víctima. Más allá del concepto de justicia transicional, el artículo hace hincapié en el reto de una elaboración hegeliana del pasado mediante la cual las lecciones históricas podrían ser transmitidas a las generaciones futuras.

Palabras clave: justicia transicional / trabajo de la memoria / guerra / revolución / pacificación 


\section{Introducción}

Con la firma del acuerdo de paz "firme y duradera" entre el gobierno guatemalteco y la Unidad Revolucionaria Nacional Guatemalteca en diciembre de 1996 terminó la época centroamericana de guerras y conflictos internos. Comunmente, cuando hablamos de las políticas de la memoria en Centroamerica nos referimos a la memoria de los acontecimientos sangrientos de las decadas de los 70 y 80 , cuando la guerra fría se extendió al puente terrestre centroamericano y se acentuó el carácter excluyente de los régimenes dictatoriales, dando lugar a la insurgencia y la represión. En los años 90, en el marco de las transiciones de la guerra a la paz negociada, las élites tenían la tarea de enfrentar, de una manera u otra, el legado de la violencia masiva.

Si bien es sabido que las vías de desarollo histórico de cada país son diferentes de las de los demás, hay que subrayar que Nicaragua posee elementos muy singulares en su historia. En 1979, el movimiento insurgente derrotó al régimen somocista y de ahí - empleando los términos de la "transitología" - vino la primera transición a la democracia (Walker, 2000). La Revolución Sandinista fue una revolución con variedad ideológica, que introdujó una multitud de proyectos y reformas sustanciales, y que experimentó un giro dramático a partir de 1981. Apoyados por los Estados Unidos, a través de la CIA, grupos contrarrevolucionarios (Contras) entraron en una guerra sucia contra el gobierno sandinista con el objetivo de derrotarlo. Los años de guerra civil dejaron decenas de miles de víctimas mortales y cientos de miles de refugiados (veáse apartado 5.2.). Los años 80 fueron una década traumatizante de sufrimiento, pero la violencia no es comparable al terror estatal que ensangrentó a El Salvador y Guatemala. Así, los instrumentos represivos aplicados para defender la Revolución fueron un modus operandi que no buscó subyugar ni disciplinar a la población nicaragüense en su conjunto. Otra vena abierta del "pasado" sandinista es la cultura política de aquellos años, que fue marcada por la consolidación de un red dominante formada por el partido (FSLN) y sus organizaciones de masas. Las relaciones entre la oposición y el bloque de poder sandinista se vieron ensombrecidas por la violación no-generalizada de derechos cívicos (libertad de expresión y prensa, derecho de reunión y manifestación).

La segunda transición a la democracia - la derrota sandinista en las elecciones generales de 1990 - fue la transición de un modelo de democracia caracterizado por el predominio del FSLN en todas las esferas de la vida pública a un modelo de "democracia defectuosa" (Merkel, 2004), una democracia sin visión institucionalista y con extendida corrupción. De ahí pasamos a otro elemento de la singularidad de la historia nicaragüense. Si bien la segunda transición a la democracia ocurrió en un momento de creciente conciencia, a nivel global, sobre la problemática de las políticas del pasado (transitional justice), en la Nicaragua pos-sandinista no hubo una política proactiva de enfrentar el pasado a través de comisiones investigativas o procesos judiciales.

Este artículo está enraizado tanto en la experiencia nicaragüense como en el discuso global sobre los límites y las posibilidades de la superación del pasado. ¿Qué reflejan la experiencia nicaragüense y el discurso global puesto uno frente al otro? Tomando esta pregunta como punto de partida, el artículo pretende poner en duda 
certezas fundamentales asociadas al discurso de transitional justice. Si la violencia masiva es el telón de fondo de las políticas de la memoria, ¿puede haber una forma colectiva del trabajo de memoria sin represión estatal masiva? Si aceptamos la idea de que una sociedad debe enfrentar un pasado sangriento para evitar que el mal asociado a un legado de violencia masiva vuelva a pasar, ¿quiénes serían los protagonistas de una debida política del pasado? ¿Cuándo se abren las ventanas de posibilidad para introducir medidas de transitional justice y cuándo se cierran? Y, sobre todo, ¿podemos identificar la extensión temporal y física del pasado? En muchos casos, las épocas de previolencia (anteguerra) y las épocas de violencia (guerra) no se difieren entre sí por el hecho de que en una hubo violencia y en la otra no, al contrario, el nivel de violencia puede ser comparable. Por tanto, se podría plantear el pensar en la importancia del "pluscuamperfecto histórico" como punto de referencia en la decisión de reelaborar "el pasado". Lo mismo aplica a la división delicada entre "el pasado" y "el presente". Reabrir el debate sobre un espectro de preguntas fundamentales nos permite refrescar el discurso que comenzó a ser aceptado en la fase de la posguerra después de 1945. A través de su precendente más reconocido el Proceso principal de Núremberg, dirigido por el Tribunal Militar Internacional en contra de 24 de los principales dirigentes y autores intelectuales del régimen nazi - el imperativo ético del tratamiento del pasado se desplegó en el mundo.

En los párrafos siguientes me ocuparé de esbozar el campo semántico asociado con las políticas del pasado. La clave y el punto de partida de la argumentación es el discurso sobre el caso alemán, que se difundió rápidamente en otras sociedades desde la década de los 60 , e inspiró el emergente discurso transnacional sobre justicia transicional. Este acercamiento semántico facilita revisiones fundamentales, y así la noción de la "superación" se contrapone con la idea de la "justicia transicional". Mientras la primera se refiere al imperativo ético y psicoanalítico de trabajar una experiencia pasada, la segunda hace hincapié tanto en los derechos de las víctimas directas como en la triple meta de paz, democratización y reconciliación. En la segunda parte esbozaré el proceso inacabado de las transiciones políticas nicaragüenses con el objetivo de agregar dudas y preguntas nuevas.

\section{La superación del pasado y otras palabras - pinceladas semánticas}

\subsection{El trabajo elaborativo y la superación del pasado}

El imperativo ético del tratamiento del pasado fue inventado después de la Segunda Guerra Mundial. Después de la victoria sobre el régimen nazi en mayo de 1945, los aliados iniciaron una fase de desmilitarización, desnazificación y reeducación (Taylor, 2011). Se puso en marcha un amplio proceso de "depuración" con el fin de eliminar las influencias nazis. La política de desnazificación fue ejecutada de distintas formas en las cuatro zonas de ocupación, y consistió en detenciones masivas, investigaciones judiciales y el sometimiento de todo adulto a una auto clasificación en cuanto a su grado de implicación en los crímenes. En la Alemania Oriental, el proceso de desnazificación fue un fracaso porque muchos de los altos 
funcionarios del régimen nazi huyeron o fueron declarados inocentes. El esfuerzo de despertar la conciencia de los alemanes a través de la "reeducación", una terapia de choque, fue considerado por Hannah Arendt como "el error particular más grave de la política norteamericana de desnazificación” (2005, p. 315). Los Juicios de Núremberg son conocidos en todo el mundo como el precedente más importante de lo que se llama justicia transicional (Tomuschat, 2006; Reginbogin \& Safferling, 2006). El juicio principal de Núremberg, dirigido en contra de 24 de los más destacados funcionarios y colaboradores del régimen nazi fue el primero en que se juzgó y sentenció a responsables de crímenes contra la humanidad. ${ }^{1}$ Además, se llevaron a cabo una serie de juicios en contra de 184 miembros de la élite nazi, entre ellos médicos, abogados, jueces, ministros, empresarios, y miembros del alto mando militar y policial. En la Alemania Occidental de la posguerra, la legitimidad de los Juicios ha sido cuestionada fuertemente.Muchos alemanes los consideraron una "justicia del vencedor", es decir, una acción de venganza ejercida por los vencedores contra los vencidos (Burchard, 2006, pp. 812-813). En general, la población no se enfrentó con su culpa y responsabilidad, sino que rechazó el veredicto percibido de la culpa colectiva. Durante el período de la ocupación se internó a decenas de miles de presuntos nazis, se juzgó a miles de presuntos implicados en crímenes de lesa humanidad (Frei, 2009, p. 87) y se revisaron los datos personales de cientos de miles de alemanes ${ }^{2}$. Sin embargo, en la Alemania Occidental se difundió un discurso de rechazo a la culpa, facilitando que la complicidad en el holocausto y los crímenes de guerra se convirtieran rápidamente en tabú.

De ser así, hay que subrayar que el debate sobre la manera adecuada de tratar los horrores del régimen nacionalsocialista tomó su contenido epistémico paradójicamente del rechazo común de la confontación crítica con el nazismo. En el trasfondo de la evolución terminológica se encuentra, en particular, el debate sobre estos mecanismos colectivos e individuales de defensa: "Debido a la discreción, practicada por la mayoría de la gente, que no sólo se refiere al ámbito particularprivado, nació el triunfo del 'callar'. La dimensión, la profundidad y el significado de este "callar" no están investigados historiográficamente ni siquiera en sus bases" (Frei, 1999, p.15, traducción de la autora). Mucho antes de que Margarete y Alexander Mitscherlich llamaran la atención sobre la "incapacidad de sentir duelo" (1994 [1967]) y antes de que Ralph Giordano postulara la "segunda culpa" (1987) de los alemanes (que resultó del rechazo de la primera culpa), se construyó la base para la amnistía y la reintegración social de los autores y autoras de los delitos. Fue este clima el que Theodor W. Adorno presenció después de su regreso del exilio y que le hizo escribir su famoso texto “Qué significa superar el pasado?”. Según Adorno (1998, p.15), se trata de

1 Once de los acusados fueron condenados a muerte, tres a cadena perpetua, cuatro a sentencias entre veinte y diez años, tres fueron absueltos y dos quedaron sin condena (Krupp por enfermedad y Ley por suicidio). Los condenados a muerte fueron ejecutados el 16 de octubre de 1946 (con excepción de Hermann Göring, quien se suicidó). Los otros fueron rechuidos en la prisión de Spandau (que albergó una sola persona de 1966 hasta 1987: Rudolf Hess, quien se suicidó en aquel año).

2 El cuestionario (Fragebogen) en inglés fue publicado en Kritz (1995, pp. 412-416). 
una formulación que [...] se ha convertido, como frase hecha, en altamente sospechosa. Cuando con ese uso lingüístico se habla de superar el pasado no se apunta a reelaborar y asumir seriamente lo pasado, a romper su hechizo mediante la clara consciencia; sino que lo que se busca es trazar una raya final sobre él, llegando incluso a borrarlo, si cabe, del recuerdo mismo.

Esta - frecuentemente citada - crítica apunta a un entendimiento psicológicosocial de los procesos subjetivos y colectivos de la posguerra alemana que implica una brecha semántica entre la "elaboración psíquica" y la "superación”. Entendido de esta forma, el planteamiento citado se refiere a un conjunto conceptual que se encuentra al centro de la teoría psicoanalítica (veáse Laplanche \& Pontalis; 1996; Jelin, 2012, pp. 47-50). Junto al término 'elaboración psíquica' (ingl.: psychological working over o out) que describe la transformación de energía por el aparato psíquico, es necesario resaltar más otros dos términos. En tanto, 'trabajo elaborativo' (ingl.: working through) hace alusión al trabajo psíquico que posibilita la superación de algo reprimido, el término 'trabajo del duelo' (ingl.: work of mourning) describe el proceso de desligarse de un objeto libidinal perdido. El trabajo doloroso del duelo es un trabajo activo dedicado a la conmemoración de cada detalle del objeto libidinal perdido (p.e. persona, idea) con el fin de que el yo salga del duelo y vuelva a ser libre, recuperando el interés por el mundo exterior.

Detrás de estos términos está la idea del trabajo que tiene que ser realizado para romper resistencias, reconocer y aceptar el pasado, y con eso posibilitar una liberación de mecanismos de repetición y momentos reprimidos del pasado. Adorno se refiere a este proceso doloroso cuando critica que en la sociedad de posguerra de la Alemania Occidental no se procuraba procesar el pasado con seriedad ni se buscaba liberarse de la maldición del pasado mediante la conciencia clara. Entendido de esa forma, el término "superar" está muy cercano a la idea hegeliana de la Aufhebung que revoca, guarda y levanta. Con el término "superación” también se puede entonces denominar el proceso reclamado por Adorno: un proceso que no descompone el pasado por la fuerza, sino que tramita el pasado activamente y así lo pone en un grado de conciencia más claro.

\subsection{De la superación a la justicia transicional}

Mientras en los años 60 fueron reflejados principalmente los resultados de la psicología social europea y estadounidense (veáse, por ejemplo, Bettelheim, 1943; Mitscherlich \& Mitscherlich, 1994 [1967]; Adorno,1998 [1959]), el aumento exponencial del debate académico sobre las políticas del pasado ocurrió en el contexto de la "tercera ola" de democratización (Huntington, 1991). Dentro de las ciencias políticas, la temática del enfrentamiento a violaciones de los derechos humanos fue tratada como un problema clave de la transición, que principalmente se refiere a: "settling a past account without upsetting a present transition" (O'Donnell \& Schmitter, 1986, p. 28). En los años 80 y 90 se pudo observar un "move from the courtroom to the hearing room" (Teitel, 2003, p.83) debido a la invención y proliferación global de la Comisión de la Verdad y Reconciliación. Cabe destacar 
que el término "justicia transicional" -incluso dentro de la propia "transitología"aún no se había convertido en una etiqueta hegemónica. Así, Timothy Garton Ash (1998, p. 35) anotó:

Yet what exactly are we talking about? There is no single word for it in the English language. German, however, has two long ones in regular use: Geschichtsaufarbeitung und Vergangenheitsbewältigung. These may be translated as 'treating' the past, 'working over' the past, 'confronting' it, 'coping, dealing or coming to terms with' it; even 'overcoming' the past. The variety of possible translations indicates the complexity of the matter at hand. Of course the absence of a word in a language does not necessarily indicate the absence of the thing it describes [...] But the presence of not just one but two German terms does indicate that this is something of a German speciality. ${ }^{3}$

Mientras la "interdisciplina" de los estudios de la Vergangenheitsbewältigung adquirió un auge notable desde los años 90 (veáse, por ejemplo, Amadiume \& AnNa'im, 2000; Barahona de Brito, González-Enríquez \& Aguilar, 2001; Elster, 2004; Hayner, 2001; Kritz, 1995; Minow, 1998; Neier, 1998), el término "transitional justice” (Siegel, 1998) empezó a establecerse. A diferencia del enfoque puramente jurídico, que lo define como "conception of justice associated with periods of political change, characterized by legal responses to confront the wrongdoings of represssive predecessor regimes" (Teitel, 2003, p.69), se divulgó un sentido más amplio. En general, se trata de un término sumamente flexible que en muchos casos se usa para designar un paquete de medidas claramente definido, entre ellas: procesos judiciales, comisiones del esclarecimiento histórico, reparaciones colectivas, resarcimiento, monumentos (International Center for Transitional Justice [ICTJ], 2009). Hay que añadir que, en años recientes, el término fue tomado por algunos autores que lo trasladaron al tratamiento de delitos como corrupción y crímenes económicos cometidos durante un perído de violencia masiva (Duthie, 2008), y al ámbito donde se cruzan las políticas de desarollo con las políticas del pasado (Carranza, 2008; Muvingi, 2009).

A finales de los años 90 comenzó la tercera fase de la historia global de mecanismos de superación que Teitel (2003, p.89) denominó "steady-state transitional justice”. Ésta se caracterizó en particular por tres factores. Se pudo, en primer lugar, observar un auge de las normas y prácticas del derecho penal internacional, en segundo lugar la profesionalización y densificación del 'transitional justice business' internacional, y en tercer lugar una brecha creciente entre transición y transitional

\footnotetext{
3 "Y pues ¿exactamente de qué estamos hablando? No existe una palabra especifica para ello en el idioma inglés. El alemán, sin embargo, tiene dos largas palabras y de uso frecuente: Geschichtsaufarbeitung y Vergangenheitsbewältigung. Estas pueden ser traducidas como 'tratar' el pasado, 'trabajar' el pasado, 'confrontar' el pasado, 'lidiar, manejar o llegar a aceptar' el pasado; incluso 'superar' el pasado. La variedad de posibles traducciones indica la complejidad del asunto. Obviamente, la ausencia de una palabra en un idioma no necesariamente significa la ausencia de la cosa que describe [...]. Pero la presencia de no sólo uno sino dos términos alemanes indica que se trata de una 'especialidad alemana' " (traducción de la autora).
} 
justice. Es importante subrayar que muchas iniciativas de justicia transicional (por ejemplo, el proyecto de la "Truth and Reconciliation Comission" canadiense o la orden de arresto emitida por la Corte Penal Internacional contra el presidente de Sudán, Omar al-Bashir) no están relacionadas a una transición política. En el contexto de la creciente aplicación de medidas de la justicia transicional, Theidon (2009, p. 295) llamó la atención sobre el "lenguaje seductor de la transición” que evoca un cambio fundamental asociado con una cierta política estatal. Entendido de esta manera, el término transitional justice se refiere sobre todo a su objetivo, el de apoyar la transición a y/o la consolidación de regímenes democráticos. Si lo entendemos así, como un concepto acuñado en la transición democrática, ¿qué significaría una justicia transicional nicaragüense? En primer lugar, tenemos que tomar en cuenta los dos momentos históricos de la transición, 1979 y 1990. ¿Cuáles son las medidas que se aplicaron en aquellos momentos y cuáles fueron los límites de la justicia transicional?

\section{La primera transición (1979): ¿Justicia transicional revolucionaria?}

\subsection{Los antecedentes}

Los principales movimientos de resistencia a la dinastía somocista (1934 - 1979) se formaron en los años 50, empezando con el movimiento opositor intelectual liberal y la oposición en gremios, sindicatos y otros partidos - y luego con la resistencia armada del Frente de Liberación Nacional (Vilas, 1992, pp. 320-321). A mediados de los años 70, la guerrilla sandinista apenas tenía una fuerza operativa de unos cientos de miembros, pero contaba con una creciente base de simpatizantes (Martí i Puig, 2004, p. 127). La clave del éxito del movimiento insurreccional fue la amplificación y densificación de un movimiento generalizado contra el régimen dictatorial que se inició después del terremoto del 23 de diciembre de 1972 que devastó grandes partes de la capital. El manejo corrupto de los fondos de la ayuda internacional reveló una vez más el carácter cleptocrático del régimen somocista, dando lugar a la ruptura definitiva de sectores poderosos de la oligarquía nicaragüense con el somocismo. La alianza entre estos sectores y el FSLN se concretizó en la aparición pública del Grupo de los Doce en 1977 (Black, 1985, p. 104). Cuando el régimen somocista asesinó al periodista Pedro Joaquín Chamorro en enero de 1978, la dictadura rompió el equilibrio frágil que se reflejaba en la norma no escrita de respetar la integridad física de la oligarquía. Al mismo tiempo, el descontento desembocó en un número de movimientos insurreccionales locales en Masaya, Matagalpa, León y Jinotega. El régimen somocista reaccionó con represión masiva, incluyendo el bombardeo de las ciudades que habían sido tomadas por el FSLN. En junio de 1979 empezó la ofensiva final de las fuerzas sandinistas que culminó en la renuncia del dictador y su fuga.

El 19 de julio de 1979, cuando cientos de miles de simpatizantes celebraron la victoria en Managua, el país se aproximó a un colapso inminente. La implosión del régimen somocista dejó un vacío de poder que debía ser llenado por las nuevas 
autoridades. En la fase inmediata del pos-somocismo - "periódicos poéticos los de los primeros días" (Cardenal, 2004, p. 298) - se puso en marcha una multitud de iniciativas populares y proyectos políticos con el objetivo general de reconstruir el país. Al mismo tiempo, el poder de la Dirección Nacional del FSLN empezó a consolidarse (Prevost, 1991). La Junta de Gobierno de Reconstrucción Nacional, fundada en Costa Rica en junio de 1979, asumió el poder ejecutivo apoyada por el Consejo de Estado. Estos ejes estatales desempeñaron un papel central en el desarrollo de la Revolución de acuerdo a los siguientes principios: Primero, se trató de una revolución que se caracterizó por el anhelo de unificar un amplio espectro de partidos políticos y sectores sociales, y entonces se instalaron varios mecanismos para la representación política de intereses diferentes. Segundo, la política del sandinismo se basó en el principio de la economía mixta, y de ser así, la Revolución Sandinista fue una revolución "con burguesía" (Cardenal, 2004, p. 306) o con el empresariado "patriota". Tercero, la Revolución Sandinista se basó en el principio del no alineamiento.

\subsection{Revolución con rostro humano}

Es importante subrayar que el salto revolucionario de 1979 se inscribió en los parámetros de la guerra civil. El país estaba en ruinas, con una sociedad desgarrada, y con múltiples luchas y triunfos locales. Mientras la cúpula del FSLN creaba las condiciones para su hegemonía política, también buscó reconstruir y transformar la patria. Aparte de la disolución de la Guardia Nacional y la creación del nuevo ejército sandinista y la Policía Nacional, hubo una simultaneidad flotante de proyectos políticos y sociales. ¿Y el legado del somocismo?

Desde antes de su victoria - anticipando lo que sería el carácter único de la Revolución Sandinista - el FSLN proclamó la estrategia de alianzas amplias como eje fundamental de su filosofía política. Y aún más, el proceso revolucionario implicó la autoimagen de una revolución con rostro humano, una revolución cultural y creativa. Esta autoimagen dejó una huella profunda en autobiografías como "El país bajo mi piel: memorias de amor y de guerra" (Belli, 2001), "Adiós muchachos" (Ramírez, 1999) o "La Revolución Perdida" (Cardenal, 2004). Así, Cardenal (2004, p. 280) anotó:

En Nicaragua estaba puesta la atención del mundo. A todos asombró la abolición de la pena de muerte. Era de esperarse todo lo contrario, sobre todo después de Irán. Radio Sandino aconsejaba compasión por los enemigos vencidos, y recomendaba a las embajadas tener abiertas las puertas para todos los que se quisieran asilar.

A esta memoria se escapan muchos de los acontecimientos más crueles. Sin embargo, aquella realidad recordada por Cardenal es un prisma que nos permite acercarnos a la realidad como ocurrió en distintos lugares del país. Cabe destacar que la política sandinista del pasado fue una política ambivalente sobre pasado, que se basó tanto en los derechos humanoscomo en los intereses estratégicos de los altos mandos sandinistas. 
Una medida importante fue la creación de un nuevo ejército, integrado por combatientes sandinistas, civiles y miembros jóvenes de la Guardia Nacional que habían desertado de las filas del dictador. Durante los primeros meses de la revolución, el ex coronel somocista Bernardino Larios ocupó el cargo de ministro de defensa (antes de ser sustuituido por Humberto Ortega, comandante en jefe del nuevo ejército sandinista). William Bowdler, el representante del gobierno de los Estados Unidos, es quien había propuesto el nombramiento de Larios durante las negociaciones sobre la transferencia del poder que se llevaron a cabo en Costa Rica a inicios de julio de 1979. Sin embargo, la designación de Larios no tuvo el efecto deseado (el de instaurar un pilar no sandinista en el gobierno). En una entrevista publicada en La Prensa el 18 de julio del 2000, Larios comentó que sus meses como ministro fueron los peores, "porque en realidad uno no quiere aceptar que está prácticamente como un títere". En aquellos meses, Humberto Ortega ya había logrado supervisar la creación del nuevo ejército sandinista. ${ }^{4}$

\subsection{Los tribunales especiales}

Aparte de esta cooptación parcial de miembros de la Guardia Nacional, la mayoría de los miembros de la Guardia Nacional fueron perseguidos por las fuerzas revolucionarias. Miles de somocistas lograron huir y entre 7 y 8 mil ex miembros de la Guardia Nacional y colaboradores civiles del régimen somocista fueron capturados y encarcelados (Catholic Institute for International Relations [CIIR], 1987, p. 48; Comisión Interamericana de Derechos Humanos [CIDH], 1981). Entonces es obvio que uno de los problemas más urgentes a resolver eran esos 7-8 mil reos somocistas que sobrepoblaron los centros penales del país.

En los primeros días de la revolución, especialmente en el mes de julio de 1979, hubo una serie de ejecuciones selectivas en contra de muchos de los feroces ex miembros de la Guardia Nacional y sus colaboradores, los odiosos "orejas" y jueces de mesta. Uno de los acontecimientos más famosos fue la captura del torturador somocista Alberto "Macho Negro" Gutiérrez el 19 de julio de 1979. Se generó una atmosfera de linchamiento y ese mismo día el asesino somocista fue baleado por un grupo de guerilleros. Otro acontecimiento, que atrajó la atención internacional, fue la ejecución extralegal de prisioneros de la cárcel "La Pólvora" en Granada (CIDH, 1981). En este contexto anómico y conflictivo la cúpula sandinista tenía que demostrar que el lema famoso "implacables en el combate, generosos en la Victoria" era un poco más que pura retórica.

Por tanto, hubo tres razones fundamentales para aplicar un mecanismo de justicia transicional: 1) evitar actos generalizados de venganza por parte de víctimas del somocismo, 2) cumplir con el deber moral de procesar y castigar a los que habían cometido graves violaciones a los derechos humanos y 3) probar y demostrar al público nacional e internacional que existía capacidad en el sandinismo para

\footnotetext{
4 Ocho meses después de su destitución, Larios fue acusado de haber preparado el secuestro de los miembros de la Dirección Nacional del FSLN. Fue encarcelado y condenado a siete años de prisión. En 1984 hubo un segundo proceso judicial y Larios, quien siempre declaró que era inocente, fue absuelto.
} 
hacer aplicar las normas internacionales de derechos humanos, a pesar de las aún persistentes hostilidades. Finalmente, una cuarta razón se relaciona con la historia misma del FSLN que fue una heterogénea alianza unida para derrocar a la dinastía somocista. En los primeros días de su nuevo existir como organización revolucionaria triunfante, el FSLN buscó hegemonizar el orden social e institucional. Hay que recordar que las estructuras fundamentales del somocismo, incluyendo a la Corte Suprema de Justicia (CSJ) y a las Cortes de Apelaciones, habían sido disueltas, dejando un vacío de poder. En general, se tuvieron que enfrentar una triple problemática. Era previsible, en un primer momento, que el problema central de la fragilidad, debilidad e inseguridad del sistema judicial no fuese susceptible a ser resuelto a corto plazo. Segundo, los nuevos magistrados de la CSJ, nombrados por la Junta de Reconstrucción antes de la caída del régimen somocista, representaron corrientes ideológicas e intereses de clase diferentes. Dentro de las filas del FSLN, por tanto, existía preocupación por un giro político que pudiera desacelerar el proceso revolucionario.Aquella preocupación, que vino apareada con las consideraciones mencionadas, abrió paso a la creación de los Tribunales Especiales de Justicia en diciembre de 1979.

El organismo judicial especial estaba formado por nueve tribunales especiales y tres tribunales de apelación. Cada tribunal constaba de tres miembros, uno de los cuales debía ser abogado o estudiante de derecho en su último o penúltimo año de estudio. Para ser miembro se requería, además, ser mayor de 21 años y ser persona de reconocida solvencia moral (cf. Decreto 185 del 29 de noviembre de 1979, Art.8). La debilidad institucional de los tribunales especiales, expresada en los requerimientos rudimentarios de calificación profesional, fue objeto de fuertes críticas. ${ }^{5}$ Sin embargo, se convirtió - desde el punto del vista del FSLN - en una fortaleza porque los que desempeñaron el papel de miembros de los tribunales eran simpatizantes del FSLN.

Según datos oficiales, 6.310 reos somocistas (es decir, militares, funcionarios y cómplices del régimen somocista) fueron procesados por los tribunales especiales (CIDH, 1981; Amnesty International, 1981). De los acusados, 1.760 fueron indultados o se beneficiaron del sobreseimiento, 229 fueron absueltos y 4.331 fueron hallados culpables y sentenciados a diferentes penas carcelarias: 1.648 a 5 años o menos, 283 a prisión o presidio de 6 a 10 años, 898 de 11 a 15 años, 277 de 16 a 20 años, 394 de 21 a 25 años, y 831 de 26 a 30 años (CIDH, 1981). En 1986, el gobierno informó que de los 4.331 reos sentenciados, 2.157 permanecían en prisión (Equipo Envío, 1987).

En conclusión, el sistema de los tribunales especiales fue deficiente pero surgió en un ambiente de inestabilidad política. Por un lado, no siempre se cumplieron los requisitos y garantías procesales, produciendo así sentencias basadas fundamentalmente en la afiliación política de los acusados y su posición dentro de la cadena de mando (Amnesty International, 1981). Sin embargo, el cuadro de esta problemática no estaría completo sin tener en cuenta el hecho de que se logró

\footnotetext{
5 Por ejemplo, Amnistía Internacional (Amnesty International, 1981, p. 16) comentó que los doce tribunales sólo contaban con seis abogados. En general, el reporte de Amnistía Internacional hace hincapié en una serie de "irregularities as regards the application and interpretation of the law" (1981, p. 35).
} 
procesar y castigar rápidamente a miles de presuntos victimarios que se encontraban en los centros de detención.

\subsection{El tiranicidio}

En la otra cara de la historia de la justicia transicional revolucionaria está el tiranicidio. Gracias a su amistad con el dictador Alfredo Stroessner, Somoza pudo exiliarse en Paraguay y al poco tiempo de su llegada siguió su carrera de enriquecimiento, realizando numerosas inversiones y adquisiciones, entre ellas, un latifundio en el Chaco. El 17 de septiembre de 1980, en una emboscada, Somoza fue asesinado por un comando guerrillero. Mientras la policía paraguaya buscó a los autores materiales del atentado, miles de nicaragüenses salieron a las calles para celebrar la "vindicta popular" (cf. El País, 19 de septiembre de 1980). Aunque posteriormente se supo que el comando guerrillero era integrado por miembros del Partido Revolucionario de los Trabajadores - Ejército Revolucionario del Pueblo (PRT-ERP), liderado por el argentino Enrique Gorriarán Merlo, hasta la fecha nadie ha sido capaz de establecer con precisión si hubo más autores intelectuales del atentado. ${ }^{6}$

En 1986, Eduardo Galeano anotó: "Tachito Somoza, destronado, desterrado, vuela por los aires en una esquina de Asunción. -¿Quién fue? - preguntan los periodistas en Managua. - Fuenteovejuna - contesta el comandante Tomás Borge" (Galeano, 2007, p. 312). "Fuenteovejuna" se refiere a la obra teatral de Lope de Vega (1618) y quiere decir "todo el pueblo" (unido en la lucha contra la tiranía). Al parecer, la opinión pública nicaragüense estaba dividida en cuanto a si era justo ejecutar el dictador con fusiles y bazuka.

\section{La segunda transición (1990): la Piñata y la pacificación}

\subsection{El reto de la desmovilización}

Los dilemas de la segunda transición política nicaragüense están claramente encadenados al contexto histórico en el que se desarollaron. En general, los acontecimientos políticos del bienio $1989-90$ se inscriben dentro del flujo de eventos históricos mundiales que culminaron en la caída del muro de Berlín y en la disolución de la Unión Soviética. Con la Perestroika y el previsible fin de la guerra fría se abrieron nuevos espacios diplomáticos en los años 80 en Centroamérica. En medio de grandes dificultades y bajo una creciente presión internacional? los presidentes de Costa Rica, El Salvador, Guatemala, Honduras y Nicaragua firmaron el acuerdo de Esquipulas II en 1987 con el objetivo de acelerar el proceso

6 En 1993 se publicó el libro "Somoza: expediente cerrado: la historia de un ajusticiamiento" (Alegría E̊ Flakoll) basado en testimonios de miembros del comando guerrillero.

7 En el caso de Nicaragua, la presión internacional se aumentó en el contexto del escándalo Irán-Contra de los años 1985-86, que reveló la venta ilegal de armas a Irán y la financiación de los grupos contrarrevolucionarios por parte de los Estados Unidos con esos recursos y con los del narcotráfico (ver informe Kerry de 1989). En 1986 la Corte Internacional de Justicia condenó al gobierno estadounidense por el apoyo a la Contra. Un cambio sustancial de la política exterior de los Estados Unidos ocurrió en 1989 cuando George Bush asumió el poder y se empezaron a concentrar los esfuerzos en el apoyo a la oposición política. 
de pacificación de Centroamérica (Goodfellow \& Morrell, 1991; Pearce, 1999). Las condiciones marco negociadas incluyeron el fin de la ayuda militar extranjera, la democratización, la reconciliación nacional y, al fin y al cabo, la promulgación de amnistías. En Nicaragua, la guerra fue crecientemente percibida como un empate lesivo ("mutually hurting stale-mate", Spalding, 1999, p. 34) cuyos fundamentos materiales se desmoronaron a medida que se desvanecieron los fondos extranjeros de apoyo. Con la inesperada derrota electoral sandinista y el cambio de gobierno, los contras perdieron su enemigo y, siendo así, se inició el desmantelamiento de la estructura de mando de los grupos contrarrevolucionarios que habían formado la Resistencia Nicaragüense (RN) en 1987. El gobierno de Chamorro siguió el curso de las negociaciones de paz, que había comenzado previamente, con el primer encuentro entre el FSLN y la RN en Sapoá y la firma de un acuerdo de cese al fuego. Pocas semanas antes de la transferencia del poder, el 23 de marzo de 1990, el alto mando de la RN y Antonio Lacayo (como representante del gobierno entrante) firmaron el acuerdo de Toncontín (Spalding, 1999, p. 38). Durante los meses siguientes, el gobierno realizó una ronda negociadora con los grupos contrarrevolucionarios principales que fue entorpecida en un primer momento por la decisión de mantener a Humberto Ortega al frente del ejército, y luego, por las divisiones internas de la Contra. La desmovilización "a paso de tortuga" (Equipo Envío, 1990) se aceleró después de la firma del Acuerdo para el Establecimiento de Polos de Desarollo entre la RN y el gobierno a finales de mayo de 1990. Como en El Salvador y Guatemala, se ofrecieron incentivos (títulos de propriedad, materiales para la construcción de viviendas, asistencia médica) a los combatientes para lograr su reinserción en la sociedad civil. Apoyados por la Organización de la Naciones Unidas para Centroamérica (ONUCA) y la Comisión Internacional de Apoyo y Verificación de la Organización de los Estados Americanos (CIAV-OAS), 22.413 combatientes de la contrarrevolución entregaron sus armas pero a los pocos meses después del desarme, el incumplimiento de muchos acuerdos con los desalzados, los planes de licenciamiento del ejército con un mínimo de prestaciones sociales y la subsecuente miseria de muchos de los ex-combatientes provocaron un proceso significativo de removilización.

\subsection{Una transición al borde de la guerra civil}

En 1992, aproximadamente 22.835 hombres habían formado nuevos grupos armados que se concentraron sobre todo en los departamentos de Jinotega, Estelí, Matagalpa, Madriz y Nueva Segovia (Armony, 1997, p. 211). Una tercera parte de los hombres armados eran recompas (recompañeros), que vivían en las mismas miserables condiciones de vida de siempre, sin expectativas. El movimiento armado de aquellos años era un movimiento heterogéneo y diverso, con cada grupo tratando de lograr sus fines particulares. Algunos grupos armados lucharon por la transformación radical del orden político y por el reparto de las tierras, otros tenían fines puramente lucrativos, pero su carácteristica común era la de atemorizar a la población local. Así, el país se encontró al borde de una guerra civil.

La estrategía que empleó el gobierno fue espontánea y desorganizada. Por un lado se otorgaron amnistías amplias como requisito indispensable para reestablecer 
el orden y disminuir la violencia. La historia de sucesivas amnistías, que había empezado con la amnistía acordada en Esquipulas y que luego se manifestó tanto en la ley de amnistía del 10 de mayo de 1990 como en la ley de amnistía del 22 de diciembre de $1991^{8}$, terminó con la tercera ley de amnistía que extendió el plazo de amnistía hasta el 28 de agosto de 1993 (CIDH, 1994). Por otro lado el gobierno de Chamorro realizó negociaciones seperadas con los grupos armados, produciendo un conjunto de más de 40 acuerdos de desmovilización. Luego de una serie de avances y retrocesos, negociaciones engañosas y levantamientos nuevos (de recontras, recompas y revueltos), el gobierno empezó a aplicar una estrategía mixta de amnistías, negociaciones y medidas de fuerza. Los conflictos armados -aún decrecientes en extensión e intensidad-sigueron siendo, por varios años, un reto político importante de la "pos-guerra" nicaragüense hasta la desaparición del Frente Unido Andrés Castro (FUAC) en 2001.

\subsection{La transición pactada}

Cuando Chamorro ganó las elecciones presidenciales, a pesar de que heredó el problema del conflicto interno, tuvo que afrontar también la aguda crisis económica. Además, Chamorro se vio obligada a realizar el amplio proceso de "desandinización" que fue planteado durante su campaña electoral. El gobierno de Chamorro, de común acuerdo con la cúpula sandinista, y con la bendición de los IFIs, aplicaron un proceso agresivo de privatización, con lo cual la economía mixta dejó de existir y se restituyeron las fuerzas de mercado.

Los parámetros de la transferencia de poder se inscribieron dentro de una larga "historia del pactismo" interelitario nicaragüense (Rovira Mas, 2009, p. 18). Con el Protocolo de Transición del Poder Ejecutivo (PTPE), firmado entre el gobierno saliente y el entrante un mes antes de la toma de posesión, se resolvió el problema de que el ejército revolucionario debía subordinarse a un gobierno neoliberal, dejando a Humberto Ortega en su cargo como jefe del ejército - aunque con la oposición de importantes miembros del gabinete de Chamorro: el vicepresidente Virgilio Godoy, el presidente de la Asamblea Nacional Alfredo César y Enrique Bolaños. Mientras este protocolo aseguró una cierta influencia política por parte del FSLN, hubo otro paquete de medidas para asegurar la base material del sandinismo. Entre el 29 de marzo y el 2 de abril de 1990, se emitieron las leyes Nº5 (Ley de Transmisión de la Propiedad de Viviendas y Otros Inmuebles Pertenecientes al Estado y sus Instituciones), Nº6 (Ley Especial de Legalización de Viviendas y Terrenos) y Nº8 (Ley de Protección a la Propiedad Agraria). Mientras la tercera ley fue diseñada para asegurar que los beneficiarios de la reforma agraria pudiesen quedarse en sus terrenos, las primeras dos dieron paso a la llamada piñata, la repartición enorme de tierras e inmuebles por parte de la élite dirigente sandinista. Este proceso continuó con la repartición de empresas estatales y con la indemnización millionaria de exproprietarios.

8 Todas fueron amnistías generales a todos los que hubiesen cometido crimes politicos o comunes asociados con los politicos. 
Dentro de la constelación nicaragüense de la transición, y a causa de lo inesperado de la derrota electoral, tanto las urgencias inmediatas impuestas por la guerra contrarrevolucionaria prolongada como la constelación de intereses políticos, impedieron que se aplicaran medidas de justicia transicional. Mientras que la administración saliente y la entrante se ocupaban en consolidarse como grupos poderosos dentro de la constelación de fuerzas políticas, hubo una fuerte presión por la recuperación de la paz. Sin embargo, en contraste con los demás países centroamericanos, en Nicaragua no hubo un fuerte movimiento de derechos humanos ni una ola internacional de reivindicaciones de justicia. Hay que subrayar que la especifidad de la situación nicaragüense radica en el apoyo signifivativo estadounidense a la contrarrevolución.

Tanto el involucramiento de agentes estadounidenses en la planificación de crímenes de lesa humanidad como el financiamiento de los grupos contrarrevolucionarios impidieron que el gobierno estadounidense reivindicara el esclarecimiento histórico de la guerra interna nicaragüense.

\section{Transiciones, conflictos y la ausencia de la víctima}

La comparación entre la primera y la segunda transición nicaragüense revela una considerable diferencia en cuanto a la sensibilidad respecto a la responsibilidad colectiva por los crímenes y explotaciones del pasado. En 1990, la disposición política para ayudar a las víctimas de la violencia masiva fue prácticamente nula. Por otro lado, en 1979 se realizó una política ambicionada que consistía tanto en determinar la culpabilidad de los victimarios como en transformar el tejido social, demostrando así un compromiso fuerte con la idea de la superación del pasado excluyente a través del trabajo colectivo de la concientización. La política sandinista tuvo efectos transformadores positivos, pero también efectos negativos fruto de la violencia que se ejerció sobre la población costeña y sobre los jóvenes que participaban en el servicio militar.

\subsection{Justicia extraordinaria y el trabajo del futuro}

Revisando los acontecimientos ocurridos durante la primera transición, hay que subrayar lo siguiente: No todo el pasado podía ser olvidado, pero en lugar de enfocarse en la restitución del daño, el proceso se centró en la responsibilidad de los perpetradores directos a nivel de soldados y colaboradores. Se buscó una respuesta inmediata al aplastante número de encarcelados de acuerdo con las normas internacionales de derechos humanos sin tener que recurrir al sistema establecido de justicia. Además, el establecimiento de los tribunales especiales fue un intento de canalizar la peligrosa rabia contra los somocistas en una dirección no-violenta. Hay que recordar que la base ideológica principal de la Revolución Cultural Sandinista fue la revolución sin la furia y el odio, y sin lo que Heinrich Heine llamó la "guillotina de vapor", es decir, una maquina de la muerte que posibiltara la ejecución en cadena.

Los años del triunfo fueron duros en la lucha por la hegemonía política, con fricciones entre los grupos con pretenciones al poder y con una división de 
trabajo entre la élite dirigente sandinista. Los que se ocuparon principalmente de lo jurídico eran juristas tratando de diseñar un cambio institucional enmarcado en un nuevo marco legal, y quienes se ocuparon del ámbito político-cultural eran los que trataban de sentar las bases para una nueva sociedad, sin ataduras ni esclavitud. En este sentido, los proyectos sustanciales impulsados durante los primeros años de la Revolución -la campaña de alfabetización, los talleres de poesía- sirvieron para fortalecer el tejido social y para concientizar a la gente. Así, el lema de la alfabetización "Y también enséñenles a leer" (Fonseca) está asociado con el esfuerzo colectivo del trabajo de la memoria. Se trató de un "aprendizaje doble: los alfabetizadores enseñaron a los campesinos, y los campesinos a los alfabetizadores" (Cardenal, 2004, p. 353). Siendo así, la campaña de alfabetización pretendió sensibilizar a los jóvenes alfabetizadores sobre la realidad social en el interior del país, convertiendo su ignorancia en compromiso social. En este sentido, la Revolución Sandinista fue una revolución positiva del comportaminto social, una revolución comprometida con el arduo trabajo colectivo cognitivo y emocional que era considerado necesario para lograr cambios habituales frente a la vida colectiva y para superar el pasado ignorante y explotador. En vez de tratar las heridas abiertas del pasado, el sueño revolucionario fue el tratamiento del presente para "construir el hombre nuevo", es decir, la transformación humana a partir de los proyectos político-culturales del pos-triunfo. Los principales destinatorios de aquel esfuerzo de transformación no eran las víctimas del somocismo, sino tanto la juventud burguesa como la población adulta analfabeta.

\subsection{Víctimas sin voz}

Al comparar las implicaciones sociales de ambas transiciones nicaragüenses, la diferencia es notable. Mientras que la primera fue una transición política con afán transformador en lo humano, la segunda fue una transición política que se limitó a cambiar el marco institucional del país. Una comparación entre la primera y la segunda transición nicaragüense revela además que las decisiones sobre la aplicación y/o omisión de medidas de justicia transicional fueron tomadas en una tensa situación estratégica, con fuerzas contrarrevolucionarias activas. Las decisiones tácticas se apoyaron principalmente en una estimación de la fuerza, composición y futura actividad del enemigo armado. A diferencia de la mayoría de los casos de justicia transicional, en Nicaragua se pasó, sin un período de transición negociada, de la dictadura al sandinismo y del sandinismo a la democracia deficitaria. Así, ante los hechos consumados de la victoria armada y la victoria electoral, se pasó a una política activa de pacificación. Mientras que en el año del triunfo revolucionario se buscó consolidar el poder político y detener al movimiento contrarevolucionario previsible, en 1990 el gobierno entrante siguió los pasos del gobierno sandinista, negociando con la Contra. En ambos casos, las víctimas de la violencia masiva, con sus necesidades y aspiraciones, no fueron tomadas en cuenta.

En general, la falta de estádisticas fiables ha hecho imposible, hasta hoy, describir el balance de las víctimas mortales con exactitud (Seligson \& McElhinny, 1996, p. 224). Mientras las estadísticas oficiales presentadas por Kornbluh (1991, p. 345 ) indican que la guerra contrarrevolucionaria causó 30.856 víctimas mortales, 
otras fuentes se refieren a un número de víctimas mortales de 4.429 (hasta el 1 de mayo de 1986) y un número de 4.900 heridos y 3.800 secuestrados (Garfield, Frieden \& Vermund, 1987). Según Seligson y McElhinny (1996), las estimaciones del número de víctimas de la guerra civil (1975-1979) varían de 10.000 a 50.000 y las cifras de la guerra contrarrevolucionaria (1980-1990) oscilan entre 23.935 y 33.935. Estas cifras son escandalosas por la magnitud de la violencia colectiva y por el hecho de que decenas de miles de nicaragüenses, que ni siquiera tenían una existencia civil, han desaparecido desde la década de los 70 .

Es imposible su cuantificación pero desde una perspectiva socio-espacial hay que subrayar que la guerra contrarrevolucionaria, en múltiples frentes y sin centro único, se extendió hacia las regiones más remotas del país, siendo la Mosquitia, Boaco, Chontales, Nueva Segovia, Matagalpa y Jinotega las regiones más afectadas por la violencia. Cuando la guerra empezó a desacelerarse en el año de la derrota electoral sandinista, una gran parte de la población nicaragüense se vió afectada directamente (Seligson \& McElhinny, 1996; Nygren, 2003). La violencia masiva dejó un saldo de aproximadamente 354.000 desplazados internos, y entre 1986 y 1993 se registraron 71.750 refugiados retornados desde los campos costarricenses y hondureños (Dye, Butler, Abu-Lughod \& Spence, 1995; Lundquist \& Massey, 2005). El proceso masivo de desmovilización dejó decenas de miles de ex-combatientes (contras y miembros del ejército sandinista) en condiciones de vida precarias y de vulnerabilidad socio-económica. En la "posguerra" nicaragüense, las seguridades de la vida humana todavía se tambaleaban, y así, la realidad diaria de la economía de sobrevivencia solía fortalecer el miedo colectivo, difuso e intenso (Withford Delgadillo, 1990).

El conflicto entre el Estado-Nación y la costa Caribe -en algunos momentos históricos latente y en otros no- volvió a aparecer poco después del triunfo. Nicaragua vivió una rápida escalada del conflicto a partir de la creación de la organización MISURASATA (Miskitu, Sumu, Rama, Sandinista, Asla Tanaka) que rechazó tanto la campaña de alfabetización castellanizante como la política sandinista de integración y nacionalización. Mientras que la dirigencia indígena, con Steadman Fagoth siendo el protagonista más conocido, empezó a convocar a medidas de resistencia en apoyo a las reivindicaciones indígenas (derechos culturales, autonomía política), el alto mando sandinista rechazó el separatismo de los caribeños. Como consecuencia, los sandinistas empezarona perseguir a la dirigencia de MISURASATA, contribuyendo así a la aceleración del conflicto. Aproximadamente 3.000 Miskitos huyeron a Honduras, donde se entrenaba en ese momento la emergente contrarrevolución. Después de las primeras acciones violentas contrarrevolucionarias, en diciembre de 1981, los sandinistas decidieron desplazar a la población de 200 aldeas del área fronteriza del río Coco, para remover la base social del movimiento contrarrevolucionario y tomar control sobre la costa Atlántica. Apróximadamente 10.000 personas huyeron a los campos de refugiados hondureños y 9.500 personas fueron realojadas en los asentamientos de Tasba Pri (Vilas, 1989, p. 150; CIDCA, 1987, p. 234). El golpe violento fue justificado con la evidente amenaza de una invasión de tropas contrarrevolucionarias desde Honduras. 


\section{Los retos de la superación del pasado}

La escalada de la violencia en la costa Caribe demuestra que detrás de las confrontaciones armadas de las últimas décadas hay una larga historia de exclusión social, con la ignorancia colonial convirtiéndose en una multidud de discursos modernistas. Esto nos indica que el primer reto de una superación del pasado consistiría en esclarecer las ficciones desarollistas, nacionalistas e integracionistas vigentes hasta el día de hoy.

El segundo reto se relaciona con la necesidad de acercarse a las experiencias de víctimas, victimarios y sobrevivientes de las guerras internas. Es de suponer que la experiencia de violencia masiva se ha traducido en una cultura de violencia que se expresa sobre todo en la aplastante violencia de género (Ellsberg, 1997).

El tercer reto consistiría en un esfuerzo común de elaborar el pasado con el fin de transmitir la experiencia a las generaciones futuras. Aquella herencia social, que se debe guardar, conservar y transmitir de generación en generación, consiste tanto en los recuerdos nostálgicos del triunfo como en los ensayos frustrantes y los errores costosos de la Revolución. El desafío, por tanto, es extraer lo malo y lo bueno de la experiencia revolucionaria para que pueda servir como recurso orientador en el futuro.

En los últimos años del siglo 20 y, más aún, en los primeros años del presente siglo se dieron los primeros pasos no estatales hacia una reelaboración del pasado nicaragüense. Aparte de una serie de biografías y relatos, aparecieron los primeros proyectos culturales importantes, entre ellos, la película "El inmortal” de Mercedes Moncada y el "Tren Cultural” del Instituto de Historia de Nicaragua y Centroamérica IHNCA.

Si aceptamos la idea de que la sociedad nicaragüense debe enfrentar su pasado para evitar que el mal asociado a un legado de violencia masiva vuelva a pasar, tenemos que tomar conciencia de las condiciones de posibilidad para un trabajo elaborativo profundo. En la Nicaragua contemporánea, las ventanas de posibilidad de introducir una verdadera política estatal del pasado están cerradas porque "el pasado" se extiende hasta el presente, con las prácticas políticas del régimen MurilloOrtega fortaleciendo el antagonismo y contradiciendo la visión de una sociedad libre.

\section{Referencias bibiliográficas}

Adorno, T. W. (1998). ¿Qué significa superar el pasado?. En T.W. Adorno. Educación para la emancipación (pp.15-29). Madrid: Ediciones Morata.

Alegría, C. \& Flakoll, D. J. (1993). Somoza: expediente cerrado: la historia de un ajusticiamiento. Managua: Editorial El Gato Negro.

Amadiume, I. \& An-Na'im, A. (Eds.) (2000). The Politics of Memory: Truth, Healing, and Social Justice. London/ New York: Zed Books.

Amnesty International [AI]. (1981). Report of the Amnesty International Missions to the Republic of Nicaragua, August 1979, January 1980 and August 1980. London: Amnesty International. 
Arendt, H. (2005). Las secuelas del régimen nazi. Informe desde Alemania [1950]. En H. Arendt. Ensayos de comprensión 1930-1954 (pp.301-326). Madrid: Capparós Editores.

Armony, A. C. (1997). The Former Contras. En T. W. Walker (Ed.). Nicaragua without Illusions. Regime Transition and Structural Adjustment in the 1990s (pp. 203-218). Wilmington: SR Books.

Ash, T. G. (1998). The Truth About Dictatorship. The New York Review of Books, 45 (3), 35-40.

Barahona de Brito, A., González-Enríquez, C. \& Aguilar, P. (Eds.) (2001). The Politics of Memory. Transitional Justice in Democratizing Societies. Oxford: Oxford University Press.

Belli, G. (2001). El país bajo mi piel. Memorias de amor y guerra. Barcelona: Plaza y Janés.

Bettelheim, B. (1943). Individual and Mass Behavior in Extreme Situations. Journal of Abnormal and Social Psychology, (38), 417-452.

Black, G. (1985). Triumph of the People. The Sandinista Revolution in Nicaragua. London: Zed Press.

Burchard, C. (2006). The Nuremberg Trial and its Impact on Germany. Journal of International Criminal Justice, 4 (4), 800-829.

Cardenal, E. (2004). La Revolución Perdida. Managua: Anamá Ediciones.

Carranza, R. (2008). Plunder and Pain: Should Transitional Justice Engage with Corruption and Economic Crimes?. International Journal of Transitional Justice, 2 (2), 310-330.

Catholic Institute for International Relations [CIIR]. (1987). Right to survive: human rights in Nicaragua. London: CIIR.

Centro de Investigación y Documentación de la Costa Atlántica [CIDCA]. (1987). Vom Rio Coco nach Tasba Pri. Chronik einer gescheiterten Umsiedlung. En K. Meschkat et al. (Eds.). Mosquitia - die andere Hälfte Nicaraguas: über Geschichte und Gegenwart der Atlantikküste (pp.219-253). Hamburg: Junius.

Comisión Interamericana de Derechos Humanos [CIDH]. (1994). Informe Anual de la Comisión Interamericana de Derechos Humanos 1993 (OEA/Ser.L/V/II.85). Capítulo IV. Recuperado el 22 de junio de 2013, de http://www.cidh.oas. org/annualrep/93span/cap.IVd.htm.

Comisión Interamericana de Derechos Humanos [CIDH]. (1981). Informe sobre la Situación de los Derechos Humanos en Nicaragua (OEA/Ser.L/V/II.53). Recuperado el 22 de junio de 2013, de http://www.cidh.org/countryrep/ Nicaragua81sp/indice.htm.

Duthie, R. (2008). Toward a Development-sensitive Approach to Transitional Justice. International Journal of Transitional Justice,2 (2), 292-309.

Dye, D. R., Butler, J., Abu-Lughod, D. \& Spence, J. (1995). Contesting Everything, Winning Nothing: The Search for Consensus in Nicaragua, 1990-1995. Hemisphere Initiatives Report, Brookline, MA: Hemisphere Initiatives. Recuperado el 22 de junio de 2013, de http://lanic.utexas.edu/project/hemisphereinitiatives/ contesting.htm.

Ellsberg, M. C. (1997). Candies in hell - Domestic violence against women in Nicaragua. Umea: Department of Epidemiology and Public Health, Umea University, Sweden. 
Elster, J. (2004). Closing the Books: Transitional Justice in Historical Perspective. Cambridge, UK: Cambridge University Press.

Equipo Envío. (1990). Los contras de Franklin: ¿cuál será su futuro? Envio, (105). Recuperado el 01 de junio de 2013, de http://www.envio.org.ni/portada. es/105

Equipo Envío. (1987). El expediente de Nicaragua en Derechos Humanos. Envío, (76). Recuperado el 01 de junio de 2013, de http://www.envio.org.ni/ articulo/535

Frei, N. (1999). Vergangenheitspolitik. Die Anfänge der Bundesrepublik und die NSVergangenheit. München: C.H. Beck (la versión en inglés fue publicada por Columbia University Press bajo el título Adenauer's Germany and the Nazi Past. The Politics of Amnesty and Integration).

Frei, N. (2009). 1945 und wir [1945 y nosotros]. München: C.H. Beck.

Galeano, E. (2007). Memoria del fuego III: El siglo del viento [1986]. Madrid: Siglo XXI. Garfield, R. M., Frieden, T. \& Vermund, S. H. (1987). Health-Related Outcomes of War in Nicaragua. American Journal of Public Health, 77 (5), 615-618.

Giordano, R. (1987). Die zweite Schuld oder Von der Last, Deutscher zu sein. Hamburg: Rasch \& Röhrig. [La segunda culpa o: la carga de ser alemán]

Goodfellow, W. \& Morrell, J. (1991). From Contadora to Esquipulas to Sapoá and Beyond. En T.W. Walker (Ed.). Revolution and counterrevolution in Nicaragua. (pp. 369-393). Boulder/San Francisco/ Oxford: Westview.

Hayner, P. (2001). Unspeakable Truths: Confronting State Terror and Atrocity. New York: Routledge,

Huntington, S. P. (1991). The Third Wave: Democratization in the Late Twentieth Century. Norman: University of Oklahoma Press.

International Center for Transitional Justice [ICTJ]. (2009). Factsheet: What is Transitional Justice?. International Center for Transitional Justice. Recuperado el 22 de junio de 2013, de http://ictj.org/sites/default/files/ICTJ-GlobalTransitional-Justice-2009-English.pdf.

Jelin, E. (2012). Los trabajos de la memoria. Lima: IEP.

Kornbluh, P. (1991). The U.S. Role in the Counterrevolution. En T.W. Walker (Ed.). Revolution and counterrevolution in Nicaragua. (pp.323-349). Boulder/San Francisco/ Oxford: Westview.

Kritz, N. J. (Ed.). (1995). Transitional Justice: How Emerging Democracies Reckon with Former Regimes. Volume III: Laws, Rulings, and Reports. Washington, D.C.: United States Institute of Peace Press.

Laplanche, J. \& Pontalis, J. B. (1996). Das Vokabular der Psychoanalyse. Frankfurt a.M.: Suhrkamp [versión en español publicada por Editorial Paidós en 1996 bajo el título Diccionario de Psicoanálisis].

Lundquist, J.H. \& Massey, D.S. (2005). Politics or Economics? International Migration during the Nicaraguan Contra War. Journal of Latin American Studies, (37), 29-53.

Martí i Puig, S. (2004).Tiranías, rebeliones y democracia: itinerarios políticos comparados en Centroamérica. Barcelona: Edicions Bellaterra.

Merkel, W. (2004). Embedded and Defective Democracies. Democratization, 11 (5), $33-58$. 
Minow, M. (1998). Between Vengeance and Forgiveness: Facing History After Genocide and Mass Violence. Boston: Beacon Press.

Mitscherlich, A. \& Mitscherlich, M. (1994). Die Unfähigkeit zu trauern [1967]. München: Piper [La incapacidad de sentir duelo].

Muvingi, I. (2009). Sitting on Powder Kegs: Socioeconomic Rights in Transitional Societies. International Journal of Transitional Justice, 3 (2), 163-182.

Neier, A. (1998). War Crimes: Brutality, Genocide, Terror, and the Struggle for Justice. New York: Times Books.

Nygren, A. (2003). Violent Conflicts and Threatened Lives: Nicaraguan Experiences of Wartime Displacement and Postwar Distress. Journal of Latin American Studies, (35), 367-393.

O’Donnell, G. \& Schmitter, P. C. (1986). Transitions from Authoritarian Rule: Tentative Conclusions about Uncertain Democracies. Baltimore/London: Johns Hopkins University Press.

Pearce, J. (1999). Peace-building in the periphery: lessons from Central America. Third World Quarterly, 26 (1), 51-68.

Prevost, G. (1991). The FSLN as Ruling Party. En T. W. Walker (Ed.). Revolution and counterrevolution in Nicaragua. (pp. 101-115). Boulder/ San Francisco/ Oxford: Westview.

Ramírez, S. (1999). Adiós Muchachos. Una memoria de la Revolución Sandinista. Madrid: Aguilar.

Reginbogin, H. \& Safferling, C. (2006). The Nuremberg Trials: International Criminal Law since 1945 / Die NürnbergerProzesse: Völkerstrafrechtseit 1945. München: Saur Verlag/Thompson.

Rovira Mas, J. (2009). Nicaragua 1979-2007. Transición a la democracia y perspectivas de su consolidación. Encuentro, (82), 6-24.

Seligson, M. A. \& McElhinny, V. (1996). Low-Intensity warfare, High-Intensity Death: The Demographic Impact of the Wars in El Salvador and Nicaragua. Canadian Journal of Latin American and Caribbean Studies, 21 (42), 211-241.

Siegel, R. L. (1998). Transitional Justice: A decade of Debate and Experience. Human Rights Quarterly, (20), 431-454.

Spalding, R. J. (1999). From Low-Intensity War to Low-Intensity Peace: The Nicaraguan Case. En C. Arnson (Ed.). Comparative Peace Processes in Latin America. (pp. 31-41). Palo Alto, CA: Stanford University Press.

Taylor, F. (2011). Exorcising Hitler: The Occupation and Denazification of Germany. London: Bloomsbury Publishing.

Teitel, R. G. (2003). Transitional Justice Genealogy. Harvard Human Rights Journal, (16), 69-94.

Theidon, K. (2009). Editorial Note. International Journal of Transitional Justice, 3(3), 295-300.

Tomuschat, C. (2006). The legacy of Nuremberg. Journal of International Criminal Justice, 4 (4), 830-844.

Vilas, C. M. (1989). State, class and ethnicity in Nicaragua: capitalist modernization and revolutionary change on the Atlantic Coast. Boulder/London: Lynne Rienner Publisher.

Vilas, C. M. (1992). Family Affairs: Class, Lineage and Politics in Contemporary 
Nicaragua. Journal of Latin American Studies, 24 (2), 309-341.

Walker, T. W. (2000). Nicaragua: Transition through revolution. En T.W. Walker \& A.G. Armony (Eds.). Repression, Resistance, and Democratic Transition in Central America. (pp. 67-88). Wilmington: SR Books.

Withford Delgadillo, J. (1990). Angst und Krieg in Nicaragua [Miedo y guerra en Nicaragua]. Bremer Beiträge zur Psychologie, (86). Bremen: Universität Bremen. 